\title{
The rising home birth trend in America
}

\section{Nurlan Aliyev ${ }^{1}$, Chastidy Roldan ${ }^{1}$, Bulent Cakmak ${ }^{2}$ *}

\author{
${ }^{1}$ Memorial Sloan Kettering Cancer Center, New York, NY, USA \\ ${ }^{2}$ Gaziosmanpasa University, Department of Obstetrics and Gynecology, Tokat, Turkey
}

Received: 28 September 2015

Accepted: 02 November 2015

\section{*Correspondence:}

Dr. Bulent Cakmak,

E-mail: drbulentcakmak@hotmail.com

Copyright: (C) the author(s), publisher and licensee Medip Academy. This is an open-access article distributed under the terms of the Creative Commons Attribution Non-Commercial License, which permits unrestricted non-commercial use, distribution, and reproduction in any medium, provided the original work is properly cited.

\begin{abstract}
In recent years home birth rates are increased in the whole world, mainly in the United States (US). Between $2004-$ 2012, non-hospital births increasing rate is $89 \%$ in the US. Home birth increased especially among the married, nonHispanic, over 35 years of age, multipar and singleton pregnancies. However the high rate of cesarean birth did not increase in recent years in the US, now it has been stable at $32 \%$. It is reported that the stability of the cesarean rate is related to rising rate of home birth. In this mini review, the rising rate of home birth and its consequences in the US were discussed.
\end{abstract}

Keywords: Home birth, Non-hospital births, Rate, United States

\section{INTRODUCTION}

Since 2004, a growing number of women in the United States (US) have opted to give birth to their babies at home. ${ }^{1}$ If this trend persists, current patterns of clinician training, resource allocation, and facility usage are likely to change as a direct result. ${ }^{2}$ Additionally, healthcare costs will most likely decline due to a reduction of obstetric procedures and interventions. ${ }^{3}$

Based on a report released by the Centers for Disease Control, out-of-hospital births have increased by $89 \%$ between 2004 and 2012. Of the entire US population, $66 \%$ of out-of-hospital births occurred at home, $29 \%$ occurred at a freestanding birthing center, and 5\% occurred at other locations, such as physician offices. ${ }^{2}$ The majority of home births occurred among married, non-Hispanic white women $>35$ years of age who were multiparous and had singleton pregnancies. ${ }^{4,5}$ Moreover, $\sim 88 \%$ of total home births were planned. ${ }^{2}$

Many women in developed countries are attempting to find the right balance between less medicalization and overall safety during the birthing process. ${ }^{6}$ According to some women, avoidance of unnecessary medical interventions in hospitals is the main reason for opting for a home birth; this may be linked to concerns regarding the increasing cesarean delivery rates in the US that rose nearly $60 \%$ from 1996 to $2009 .^{4,7}$ This rapid increase occurred without evidence of decreasing maternal or neonatal morbidity or mortality, and is particularly concerning because all previous attempts to reverse this trend have been unsuccessful. ${ }^{8}$ As of 2012, the cesarean delivery rate in the United States was stable at $32.8 \%$. This increase has also prompted the American College of Obstetricians and Gynecologists to call for a reduction of non-medically indicated cesarean deliveries. ${ }^{4}$ A large population-based study out of Canada found that the risk of severe maternal morbidities has increased threefold for cesarean delivery as compared with vaginal delivery (2.7 vs. $0.9 \%$, respectively). ${ }^{9}$

For some women, opting for a home birth yields significant cost savings. ${ }^{7}$ The US spends $\$ 98$ billionwhich is more than any other nation - on healthcare, with a large portion of it going toward maternity care. ${ }^{10}$ Reduced rates of obstetric procedures and interventions may result in significant cost savings and increased health benefits for low-risk women who give birth outside of the hospital. ${ }^{3}$ For another group of women, opting for a home birth the 
main factors that affect their choice of where they will give birth are level of safety, previous negative hospital experience, familiarity of environment, ability to control the environment, process of care. ${ }^{3,7}$ A substantial number of women equated medical intervention with reduced safety and reported that they trusted the inherent ability of their body to give birth without interference. ${ }^{7}$

From 2004 to 2012, those giving birth in locations other than hospitals typically fit into the low-risk profile. ${ }^{2}$ There were fewer teens and older mothers who gave birth either at home or in birth centers, and there were fewer babies born preterm and/or in lower birth weight range. ${ }^{11}$ The low-risk profile of out-of-hospital births suggests that appropriately selecting low-risk women as candidates for out-of-hospital birth is occurring within the US. ${ }^{12}$ Overall safety of high-risk pregnancy home births requires closer examination since it is unclear whether the increased mortality associated with high-risk women who plan home births is causally linked to birth setting or if it is consistent with the expected increase in the rate of adverse outcomes associated with complications. ${ }^{3}$ Large population-based study has shown that complicated births must take place in maternity homes or hospitals. ${ }^{6}$

At the 2011 Home Birth Consensus Summit, maternity care experts echoed the need for effective practice guidelines. ${ }^{13}$ Incorporation of evidence-based guidelines was recommended by the Home Birth Consensus Summit is the current standard employed by the American College of Nurse-Midwives. ${ }^{14}$ Developing and implementing nationally recognized and evidence-based home birth guidelines may be one way to foster a common approach to safe home birth practices. Implementation of guidelines ensures optimal patient care and is becoming increasingly central to reimbursement and medico-legal support. ${ }^{14}$

A study of 16,924 women who planned midwife-led home births in the United States showed that low-risk women experienced high rates of physiologic birth and low rates of intervention without an increase in adverse outcomes. ${ }^{15}$ Midwifery services, which include family planning, have been shown to reduce maternal, fetal, and neonatal deaths in one study. ${ }^{3}$ In $2009,62 \%$ of home births were attended by midwives - $19 \%$ by certified nurse - midwives and $43 \%$ by certified professional midwives of direct - entry midwives. By contrast, $7 \%$ of hospital births were attended by midwives and only $5 \%$ of home births were attended by physicians. For hospital births, 92\% were attended by physician. ${ }^{1}$ A scale-up of midwifery could prevent more neonatal deaths than a scale-up of obstetrics alone; however, obstetricians can prevent a greater number of maternal and fetal deaths due to their ability to perform cesarean sections. ${ }^{3,16}$ These results suggest that midwifery alone can be an efficient and cost-effective option for achieving large reductions in mortality rates. ${ }^{3}$ A specific midwifery competency, breastfeeding counseling, is the main reason that midwives have achieved greater reductions in neonatal deaths than obstetricians. ${ }^{16,17}$ The majority $(86 \%)$ of newborns delivered by midwives were exclusively breastfed by 6 weeks of age. Combination of midwives and obstetricians led births also costs considerably less than obstetricians alone. This is most likely because there is a more cost-effective workload distribution. The most effective strategy might be the most comprehensive - increasing the use of midwives, obstetricians, and family planning could prevent $69 \%$ of total deaths under a universal scale-up, thereby yielding a cost of just $\$ 2,100$ per death prevented. ${ }^{3}$

In developing countries, nearly 1 in 4 women continue to be either alone or with only a relative/neighbor during childbirth; this rate has not changed since the early 1990s. ${ }^{8}$ The main obstacles to expansion of care in developing countries are dire scarcity of skilled providers and health system infrastructure, substandard quality of care, and reluctance by women to opt for costly maternity care. Thus, evidence from many developing countries with massive deprivation and where maternal mortality is high suggests that sheer absence of staff and facilities are the most substantial barriers to progress. ${ }^{6,8}$

\section{CONCLUSION}

Despite research results pointing toward home births being the safer option compared with hospital births for women with low-risk pregnancies, scientific investigations are ongoing to measure perinatal mortality rates in home births. Public health authorities are worried that a common approach to safe home birth midwifery practices may further support women who desire home birth as a model of care. Special emphasis is placed on the importance of having access to antenatal visits and emergency services for pregnant women as key focus areas in the fight to improve maternal and newborn health outcomes.

\section{Funding: No funding sources Conflict of interest: None declared Ethical approval: Not required}

\section{REFERENCES}

1. MacDorman MF, Mathews TJ, Declercq E. Home births in the United States, 1990-2009. NCHS Data Brief. 2012;84:1-8.

2. MacDorman MF, Matthews TJ, Declercq E. Trends in out-of-hospital births in the United States, 1990-2012. NCHS Data Brief. 2014;144:1-8.

3. Bartlett L, Weissman E, Gubin R, Patton-Molitors R, Friberg IK. The impact and cost of scaling up midwifery and obstetrics in 58 low- and middleincome countries. 2014;9:e98550.

4. Hamilton BE, Martin JA, Ventura SJ. Births: preliminary data for 2012. Natl Vital Stat Rep. 2013;62:1-20.

5. MacDorman MF, Declercq E, Menacker F. Trends and characteristics of home births in the United States by race and ethnicity, 1990-2006. Birth. 2011;38:17-23.

6. Koblinsky MA, Campbell O, Heichelheim J. Organizing delivery care: what works for safe 
motherhood? Bull World Health Organ. 1999;77:399406.

7. Boucher D, Bennett C, McFarlin B, Freeze R. Staying home to give birth: why women in the United States choose home birth. J Midwifery Womens Health. 2009;54:119-26.

8. Koblinsky M, Matthews Z, Hussein J, Mavalankar D, Mridha MK, Anwar I. Lancet Maternal Survival Series steering group. Going to scale with professional skilled care. Lancet. 2006;368:1377-86.

9. American College of Obstetricians and Gynecologists; Society for Maternal-Fetal Medicine. Obstetric care consensus no. 1: safe prevention of the primary cesarean delivery. Obstet Gynecol. 2014;123:693-711.

10. Cheyney M, Everson C, Burcher P. Homebirth transfers in the United States: narratives of risk, fear, and mutual accommodation. Qual Health Res. 2014;24:443-56.

11. Martin JA, Hamilton BE, Osterman MJK, Curtin SC, Mathews TJ. Births: Final Data for 2013. National Vital Statistics Reports. 2015;64:1-68.

12. MacDorman MF, Declercq E, Mathews TJ. Recent Trends in Out-of-Hospital Births in the United States. J Midwifery Womens Health. 2013;58:494-501.

13. Vedam S. In search of a common agenda for planned home birth in america. J Perinat Educ. 2012;21:67-71.
14. Cook E, Avery M, Frisvold M. Formulating evidencebased guidelines for certified nurse-midwives and certified midwives attending home births. J Midwifery Women's Health. 2014;59:153-9.

15. Cheyney M, Bovbjerg M, Everson C, Gordon W, Hannibal D, Vedam S. Outcomes of care for 16,924 planned home births in the United States: the Midwives Alliance of North America Statistics Project, 2004 to 2009. J Midwifery Women's Health. 2014;59:17-27.

16. Pattinson R, Kerber K, Buchmann E, Friberg IK, Belizan M, Lansky S, et al.; Lancet's Stillbirths Series steering committee. Stillbirths: how can health systems deliver for mothers and babies? Lancet. 2011;377:1610-23.

17. Black RE, Allen LH, Bhutta ZA, Caulfield LE, de Onis M, Ezzati M. Maternal and Child Undernutrition Study Group. Maternal and child undernutrition: global and regional exposures and health consequences. Lancet. 2008;371:243-60.

Cite this article as: Aliyev N, Roldan C, Cakmak B. The rising home birth trend in America. Int J Reprod Contracept Obstet Gynecol 2015;4:1669-71. 